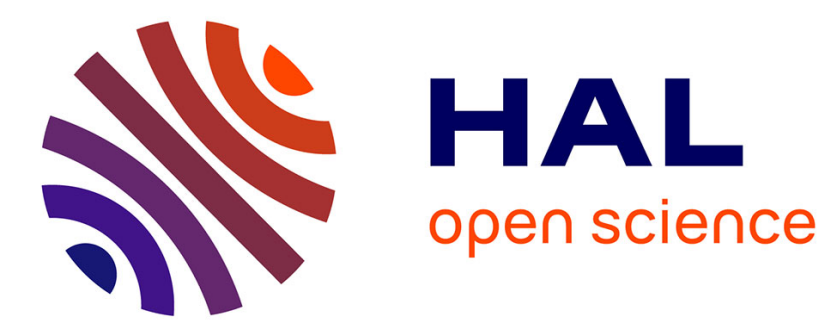

\title{
Does wearing shoes affect your biomechanical efficiency?
}

Guillaume Rao, Nicolas Chambon, Nils Guéguen, Eric Berton, Nicolas

Delattre

\section{To cite this version:}

Guillaume Rao, Nicolas Chambon, Nils Guéguen, Eric Berton, Nicolas Delattre. Does wearing shoes affect your biomechanical efficiency?. Journal of Biomechanics, 2015, 48 (3), pp.413-417. 10.1016/j.jbiomech.2014.12.038 . hal-01442054

\section{HAL Id: hal-01442054 \\ https://hal.science/hal-01442054}

Submitted on 15 Nov 2017

HAL is a multi-disciplinary open access archive for the deposit and dissemination of scientific research documents, whether they are published or not. The documents may come from teaching and research institutions in France or abroad, or from public or private research centers.
L'archive ouverte pluridisciplinaire HAL, est destinée au dépôt et à la diffusion de documents scientifiques de niveau recherche, publiés ou non, émanant des établissements d'enseignement et de recherche français ou étrangers, des laboratoires publics ou privés. 


\title{
Does wearing shoes affect your biomechanical efficiency?
}

\author{
Guillaume Rao $^{\mathrm{a}, *}$, Nicolas Chambon ${ }^{\mathrm{a}, \mathrm{b}}$, Nils Guéguen ${ }^{\mathrm{b}}$, Eric Berton ${ }^{\mathrm{a}}$, Nicolas Delattre ${ }^{\mathrm{b}}$ \\ aix-Marseille University, CNRS, ISM UMR 7287, 13288 Marseille, France \\ b Oxylane Research, Decathlon Campus, 4 boulevard de Mons, 59665 Villeneuve d'Ascq, France
}

\section{A R T I C L E I N F O}

\section{Article history:}

Accepted 18 December 2014

\section{Keywords:}

EMG-Driven model

Running

Muscle-Tendon

Footwear

\begin{abstract}
A B S T R A C T
Studies involving minimalist shoes have dramatically increased this past 10 years. While a deeper knowledge of the related modifications has ensued regarding the kinematics, electromyographic, and dynamic patterns, little is known regarding the modifications at the muscle forces and muscle fiber levels. The aim of the present study was to assess at a muscular level the modifications brought up when running barefoot, using $0 \mathrm{~mm}$ midsole height running shoe, or using classical midsole height running shoes. An EMG-Driven model that combines the kinematics, dynamics, and electromyographic data was used to estimate the Triceps Surae (TS) muscle forces and fiber behavior during running using different footwear conditions. Despite differences at the joint level between barefoot and shod running when looking at ankle joint range of motion, or foot-ground angle at touchdown, the results showed no effect of footwear neither on the maximal muscle forces nor on the relative amount of force produced by each muscle within the TS muscle group when wearing different footwear. On the contrary, different behaviors of muscle fibers were shown with lower amplitudes of fiber lengths for the Gastrocnemii biarticular muscles when running barefoot. This particular results reveal that wearing a shoe, even with a very thin sole, could deeply modify the intricate muscle-tendon mechanics of running.
\end{abstract}

(c) 2015 Elsevier Ltd. All rights reserved.

\section{Introduction}

A Pubmed search using "barefoot running" or "minimalist running" returns over 160 matches. More than 130 of these studies have been published since 2000 , denoting a striking growing interest in research on this topic for these last years.

Effects of barefoot and minimalist shoe on running pattern have been widely studied and authors consistently observed shorter stride length, shorter contact time and higher stride frequency in barefoot running compared to classical shod running (De Wit et al., 2000; Divert et al., 2005b). Many kinematic differences were highlighted between barefoot and shod running in habitually shod runners. Some authors have observed at touch-down a flatter foot and a more plantar-flexed ankle in barefoot running (Chambon et al., 2014; De Wit et al., 2000; Hamill et al., 2011). Moreover, it has been shown that foot eversion and internal tibial rotation were increased during barefoot running (Barnes et al., 2010; Fukano et al., 2009). These kinematic variations seem to be accompanied by muscular adaptations mainly located around the ankle joint. Indeed, greater tibialis anterior preactivation (von Tscharner et al., 2003) and lower preactivation of the three calf muscles (Divert et al., 2005b) during shod running compared to barefoot running have been observed.

\footnotetext{
* Corresponding author. Tel.: +33 4911704 22; fax: +33 491172252 .

E-mail address: guillaume.rao@univ-amu.fr (G. Rao).
}

These kinematic and muscular adaptations may influence body loading characteristics, but all previous observations did not converge. Some studies have shown a decrease of the first Ground Reaction Force (GRF) peak in barefoot condition (Divert et al., 2005b; Hamill et al., 2011), while others observed no difference (De Wit et al., 2000; Paquette et al., 2013). Concerning loading rate, the reported results diverge largely according to the studies that showed an increase (Chambon et al., 2014; De Wit et al., 2000; Paquette et al., 2013) or a decrease (Hamill et al., 2011) during barefoot versus shod running. The different levels of subject experience in barefoot running may explain the diverging results. Indeed, habitually barefoot runners tend to strike the ground on midfoot/forefoot, sometimes showing an absence of first peak on vertical GRF (VGRF) (Lieberman et al., 2010), with this result not being always confirmed (Hatala et al., 2013). Comparing barefoot and shod running using inverse dynamics, Kerrigan et al. (2009) have observed an increase of joint torques at ankle, knee and hip level for shod running. Divert et al. (2005a) have shown an increase of leg stiffness during barefoot running, while Hamill et al. (2011) have shown an increase of ankle stiffness.

While all the above studies focused on experimental data, none is sufficient to explain as a whole the running pattern. Muscle force represents a key variable that encompass all the above-mentioned factors into a single easily interpretable data, which can be a highly valuable addition to the experimental data. Indeed, the muscle force used to set a segment in motion or produce a force against an external 
support depends on muscle activation (usually measured using electromyography), fiber length and velocity (through the forcelength-velocity relationship), and moment arm (Buchanan et al., 2004; Lloyd and Besier, 2003). Each of the classically studied parameter (i.e., muscle activation, joint kinematics, and ground reaction force) could only exhibit little to no effect of minimalist footwear. However, a variable such as muscle force combining some of these parameters in an intricate way could present stronger and clearer evolution patterns in between shod and barefoot running. Moreover, as previously shown during hopping and running, fiber lengths trajectories estimated from an EMG-Driven model are pretty close to those measured using ultrasonography (Gerus et al., 2012). The aim of the present study was to investigate the effect of barefoot, minimal, and classical thickness footwear at the level of muscle forces and muscle fiber behavior.

\section{Methods}

Eight male subjects $(23.8+3.7$ years, $176+4 \mathrm{~cm}, 69.8+5.6 \mathrm{~kg})$ agreed to participate in the experiment and gave informed written consent. The experiment was approved by the local ethical committee. All of them were habitually shod runners without having already experienced running using minimalist shoes.

\subsection{Experimental conditions}

Three types of footwear were tested during the experiment; no shoe: Bare condition (barefoot running condition, $0 \mathrm{~mm}$ heel to toe drop), minimalist shoe: $00 \mathrm{~mm}$ condition (no EVA midsole, $3 \mathrm{~mm}$ rubber outsole, $0 \mathrm{~mm}$ heel to toe drop), classical thickness shoe: $16 \mathrm{~mm}$ condition (16 mm EVA midsole, $3 \mathrm{~mm}$ rubber outsole, $0 \mathrm{~mm}$ heel to toe drop). The uppers and drops of these prototype shoes were identical for the minimalist and regular running shoes in order to avoid any unwanted effect of these factors (Morio et al., 2009). For each subject, 3 min of treadmill running at $3.33 \mathrm{~m} \mathrm{~s}^{-1}$ was allowed in order for them to adapt to the footwear condition. Then, the subjects were asked to run indoor at $3.33 \mathrm{~m} \mathrm{~s}^{-1}$ along a track. Five trials for each footwear condition were recorded. The speed was controlled using photocells and all the subjects' speeds were between 3.27 and $3.39 \mathrm{~m} \mathrm{~s}^{-1}$. Three $5 \mathrm{~s}$ isometric Maximal Voluntary Contraction (MVC) trials with 1-min rest in between were performed for ankle plantarflexion and dorsiflexion before the running trials. For these MVC tasks, the subjects sat on a chair with their foot set into a shoe firmly fixed on the ground. Verbal encouragements were given during each MVC to ensure maximal activation of the muscles.

\subsection{Data acquisition and processing}

Three-dimensional kinematics data were recorded using 40 markers located over the subject lower limbs and torso and sampled at $125 \mathrm{~Hz}$ using an 8 cameras Vicon system. Ground reaction force data of the right foot were recorded using a Kistler (Kistler 9281 CA, dimensions: $600 \times 400 \mathrm{~mm}^{2}$ ) force plate sampled at $2000 \mathrm{~Hz}$. The force plate was located at $10 \mathrm{~m}$ from the beginning of the running track. Electromyographic data of the Tibialis Anterior (TA), Lateral Gastrocnemius (LG), Medial Gastrocnemius (MG), and Soleus (SL) muscles were recorded at $2000 \mathrm{~Hz}$ using a Trigno Delsys wireless EMG system. All data were acquired synchronously using the Vicon Nexus software.

A generic model of the human body including the head, trunk, and lower limbs segments was created in Opensim (Delp et al., 2007). This model comprises 2 degrees of freedom to represent the ankle joint (one for flexion-extension and one-located at the subtalar joint-for the pronation-supination), one degree of freedom at the knee joint to represent the flexion-extension ( 2 additional translational degrees of freedom are dependent on the angular one), and 3 degrees of freedom at the hip joint. This model also comprised the Tibialis Anterior, Gastrocnemius Lateralis, Gastrocnemius Medialis, and Soleus muscles considered as the main contributors of the ankle joint flexion/ extension movement. This generic model was scaled to match the subject's anthropometric measurements based on experimentally measured marker positions from static poses. In order to reduce the measurements errors due to marker movement on the subject's skin, an inverse kinematics algorithm was used to solve for the minimum difference between experimental and virtual markers (Delp et al., 2007). For this inverse kinematics step based on the difficulty to assess the sole mechanical characteristics during the complete stance phase, the ground contact model was kept identical for all the experimental conditions. The outputs of this inverse kinematics step consisted in ankle, knee, and hip joint angles through time. By combining kinematics, anthropometric, and force plate data, this model was further used to estimate the muscle-tendon lengths and moment arms for each muscle as well as the ankle net joint torque.

EMG data of the four muscles investigated in this study were band pass filtered (Butterworth zero time lag, 4th order, $10-450 \mathrm{~Hz}$ ), full wave rectified, and low pass filtered (Butterworth zero time lag, 4th order, $5 \mathrm{~Hz}$ ). The EMG data from the MVC trials were processed in the same way. Then, the overall maximum of each muscle
MVC was used to normalize the remaining data set. The force plate was used to detect heel contact and toe off instants and a time window from $150 \mathrm{~ms}$ before ground contact to toe off was used to analyze the data of processed EMG, muscletendon lengths, moment arms and net joint torque.

\subsection{Estimation of muscle forces}

The EMG-driven model used to estimate the muscle forces has already been extensively presented (Buchanan et al., 2004; Lloyd and Besier, 2003) and only a brief description is given here. For each muscle included in the study, a Hill-type muscle model was used to estimate the muscle forces and corresponding joint moment. This Hill-type muscle model was driven by EMG data following an EMG to activation step. The parameters characterizing each muscle force production capacity were adapted from Arnold et al. (2010), which consisted in resting pennation angle, maximum isometric force, tendon slack length and optimal fiber length. In order to tune each of the mode parameter, a simulated annealing constrained optimization scheme was used. The optimization criterion consisted in minimizing the difference between the experimentally computed ankle net joint torque and the net joint torque simulated by the EMGdriven model. Following this optimization step, the model can be considered as subjectspecific and is thus able to estimate muscle forces individually for each subject.

\subsection{Dependent variables}

The goodness of fit between the experimentally computed ankle net joint torque and the net joint torque simulated by the EMG-driven model was assessed through the coefficient of determination $\left(r^{2}\right)$ and Root Mean Square (RMS) values.

Over the stance phase, the influence of footwear was tested on the maximal value of the flexion/extension ankle net joint torque as well as on maximal normalized EMG, maximal and mean values of force for each muscle of the plantar flexor group. Moreover, the relative contribution of each muscle to the force of the Triceps Surae (TS) muscle group (sum of LG, MG, and SL muscles) was computed at the time instant when the TS force was maximal. Based on the outputs of the EMGdriven model, the mean values of the normalized fiber length as well as the amplitude values of the fiber lengths were studied during the stance phase for each muscle of the TS muscle group.

\subsection{Statistics}

Standard statistical methods were used in the calculation of means and standard deviation of the parameters studied for each participant and each condition. One-way repeated measures Analysis of Variance $\left({ }^{\mathbb{B}}\right.$ Statistica, Statsoft $)$ were used to test the influence of the footwear factor on each dependant variables. All significant effects $(p<0.05)$ were followed by Tukey posthoc tests.

\section{Results}

Given the similar running speeds, the three experimental conditions were equivalent regarding the maximal absolute value of the ankle flexion-extension net joint torque $(-185.6 \pm 27.9 \mathrm{~N} \mathrm{~m}$ for $00 \mathrm{~mm}$, $-172.8 \pm 47.0 \mathrm{~N} \mathrm{~m}$ for $16 \mathrm{~mm}$, and $-195.1 \pm 11.7 \mathrm{~N} \mathrm{~m}$ for Bare).

Significant differences $\left(F_{12,2}=12.57, p<0.05\right)$ on kinematics showed that foot angle at touch-down was lower for the Bare condition $\left(2.06 \pm 9.12^{\circ}\right)$ relative to the $00 \mathrm{~mm}\left(12.24 \pm 14.9^{\circ}\right)$ and $16 \mathrm{~mm}$ $\left(12.69 \pm 13.43^{\circ}\right)$ conditions. The ankle joint amplitude during the stance phase was significantly $\left(F_{12,2}=5.65, p<0.05\right)$ greater for the Bare condition $\left(29.47 \pm 9.52^{\circ}\right)$ than for the $0 \mathrm{~mm}$ and $16 \mathrm{~mm}$ conditions ( $23.66 \pm 12.11^{\circ}$ and $25.79 \pm 12.77^{\circ}$ respectively).

The maximal activations were not different in between the footwear conditions. Values for the LG muscle were $46.01 \pm 21.02 \%$, $50.57 \pm 12.42 \%$, and $54.85 \pm 17.89 \%$ MVC for the $00 \mathrm{~mm}, 16 \mathrm{~mm}$, and Bare conditions respectively. Values for the MG muscle were $69.26 \pm 27.35 \%, 60.11 \pm 20.48 \%$, and $71.18 \pm 25.22 \%$ MVC for the $00 \mathrm{~mm}, 16 \mathrm{~mm}$, and Bare conditions respectively, and $60.03 \pm$ $19.69 \%, 63.55 \pm 26.11 \%$ and $67.18 \pm 23.95 \%$ MVC for the Soleus muscle for the $00 \mathrm{~mm}, 16 \mathrm{~mm}$, and Bare conditions respectively. The Tibialis Anterior muscle maximal activation was not affected by footwear with maximal values of $41.14 \pm 10.28 \%, 47.54 \pm 24.02 \%$, and $35.53 \pm 7.41 \%$ MVC for the $00 \mathrm{~mm}, 16 \mathrm{~mm}$, and Bare conditions respectively.

Regarding the outputs of the EMG-driven model, the optimization process resulted in good agreements between the experimentally computed ankle net joint torque and the net joint torque 
simulated by the EMG-driven model with $r^{2}$ values of $0.90 \pm 0.04$, $0.89 \pm 0.05$, and $0.92 \pm 0.04$ and RMS values of $21.10 \pm 10.33$, $17.30 \pm 9.23$, and $13.62 \pm 8.83 \mathrm{Nm}$ respectively for the $00 \mathrm{~mm}$, $16 \mathrm{~mm}$, and Bare conditions.

The maximal muscle force was not affected by the footwear factor (Fig. 1) with maximal values for the LG muscle of $432.96 \pm 226.09 \mathrm{~N}$, $514.09 \pm 269.64 \mathrm{~N}$, and $508.97 \pm 353.35 \mathrm{~N}$ for the $00 \mathrm{~mm}, 16 \mathrm{~mm}$ and Bare conditions. Similarly, maximal forces for the MG muscle did not show any modification due to footwear $(1650.03 \pm 644.12 \mathrm{~N}$, $1380.19 \pm 524.33 \mathrm{~N}$, and $1272.83 \pm 285.30 \mathrm{~N}$ respectively for $00 \mathrm{~mm}$, $16 \mathrm{~mm}$, and Bare condition). Soleus maximal muscle forces were also not affected by the different conditions, with mean values of $3913.57 \pm 955.02 \mathrm{~N}, 3662.14 \pm 1325.40 \mathrm{~N}$, and $4417.13 \pm 627.53 \mathrm{~N}$ for the $00 \mathrm{~mm}, 16 \mathrm{~mm}$, and Bare conditions.

The overall force generated by the Triceps Surae muscle group (sum of gastrocnemii and soleus muscle forces) was also not modified by footwear (mean values for $00 \mathrm{~mm}, 16 \mathrm{~mm}$, and Bare: $5884.11 \pm 834.02 \mathrm{~N}, 5411.48 \pm 1750.21 \mathrm{~N}$, and $6046.003 \pm 412.44 \mathrm{~N})$.

The relative amount of force produced by each muscle within the Triceps Surae group was also similar across conditions with the LG muscle producing in average $8.14 \%$, the MG muscle $23.31 \%$, and the Soleus muscle $68.55 \%$ of the maximal muscle group force (Fig. 2).

Among all the variables investigated in this study, the amplitude of fiber length of the MG and LG muscles during the stance phase showed a significant effect of the footwear factor (Fig. 3). Indeed, lower amplitudes of fiber length were reported for the MG muscle in Bare condition $(2.16 \pm 0.54 \mathrm{~cm})$ relative to the $00 \mathrm{~mm}(2.83 \pm 0.29 \mathrm{~cm})$ and $16 \mathrm{~mm}(2.72 \pm 0.54 \mathrm{~cm})$ conditions. Similarly, the LG muscle showed significantly reduced fiber length amplitude for Bare compared to $00 \mathrm{~mm}$ and $16 \mathrm{~mm}$ conditions $(2.38 \pm 0.78 \mathrm{~cm}, 2.92 \pm 0.31 \mathrm{~cm}$, and $2.83 \pm 0.31 \mathrm{~cm}$, respectively). Contrary to the MG and LG muscles, the Soleus muscle showed similar amplitudes for all the footwear conditions $(2.04 \pm 0.94 \mathrm{~cm}, 2.03 \pm 0.64 \mathrm{~cm}$, and $1.93 \pm 0.65 \mathrm{~cm}$ respectively for $00 \mathrm{~mm}, 16 \mathrm{~mm}$, and Bare conditions).

Mean values of the normalized fiber length over stance phase did not show any effect of the footwear factor with averaged values over the entire footwear conditions of $0.96 \pm 0.03$ for the LG muscle, $0.98 \pm 0.02$ for the MG muscle, and $1.01 \pm 0.09$ for the Soleus muscle.

\section{Discussion}

The growing body of literature concerning minimalist running produces conflicting evidence concerning the running pattern spontaneously adopted by the runners when wearing minimalist shoes or barefoot. While habitually barefoot runners exhibit specific running patterns (i.e., mid or forefoot strike) and $80 \%$ of the habitually shod runners present a rear-foot strike (Williams et al., 2000), it is not known whether this change in running pattern comes with altered muscle forces and muscle fiber behavior during the activity. Eight habitually shod runners ran at $12 \mathrm{~km} \mathrm{~h}^{-1}$ under 3 different footwear conditions (i.e., barefoot, with minimalist running shoes, and with regular running shoes) while kinematics, dynamics, and electromyographic data were recorded and further used in an EMG-driven model to estimate muscle forces and muscle fiber behavior. Analyzing muscle forces provides a time varying information that takes into account all the modifications that occur at the kinematic, dynamic, and muscle activation levels (Buchanan et al., 2004). Moreover, supplementary information, such as the behavior of the muscle fibers during the contraction, is also available through the musculoskeletal model giving an insight on the way the muscle operates to produce the force (Gerus et al., 2012).

First, the most striking result of the present study is the absence of significant difference due to footwear (classical: $16 \mathrm{~mm}$ or minimalist: $00 \mathrm{~mm}$ ) when investigating electromyographic, joint kinematics, or joint torque data when comparing classical running shoes (16 mm of EVA in the midsole, zero drop) and minimalist shoes ( $00 \mathrm{~mm}$ of midsole, zero drop). It should be stated that a high inter-subject variability was reported in the data, particularly when looking at EMG activities. Such a high variability is not uncommon, as Hug et al. (2010) already showed such results for highly trained cyclist, but can probably preclude some significant differences among footwear conditions to be detected. While the ground reaction force is used to assess the harmfulness of the impact (Lieberman et al., 2010; Hamill et al., 2011), the data investigated in the present study are frequently used to characterize the way the subjects adapt their running patterns to the experimental conditions.

On the contrary, significant differences on ankle and foot kinematics were present in between shod and barefoot running and, as previously reported, our results showed that the foot is flatter at touch-down in barefoot than in shod condition corresponding to a fore- or mid-foot strike for barefoot. Moreover, the range of motion of the ankle joint during the stance phase was higher for barefoot than for shod running.

From our results, changing the shoe thickness had no effect on the physiological (i.e., EMG) or the mechanical cause of motion (i.e., net joint torques computed by inverse dynamics or muscle forces estimated using the EMG-driven model) during the stance phase.

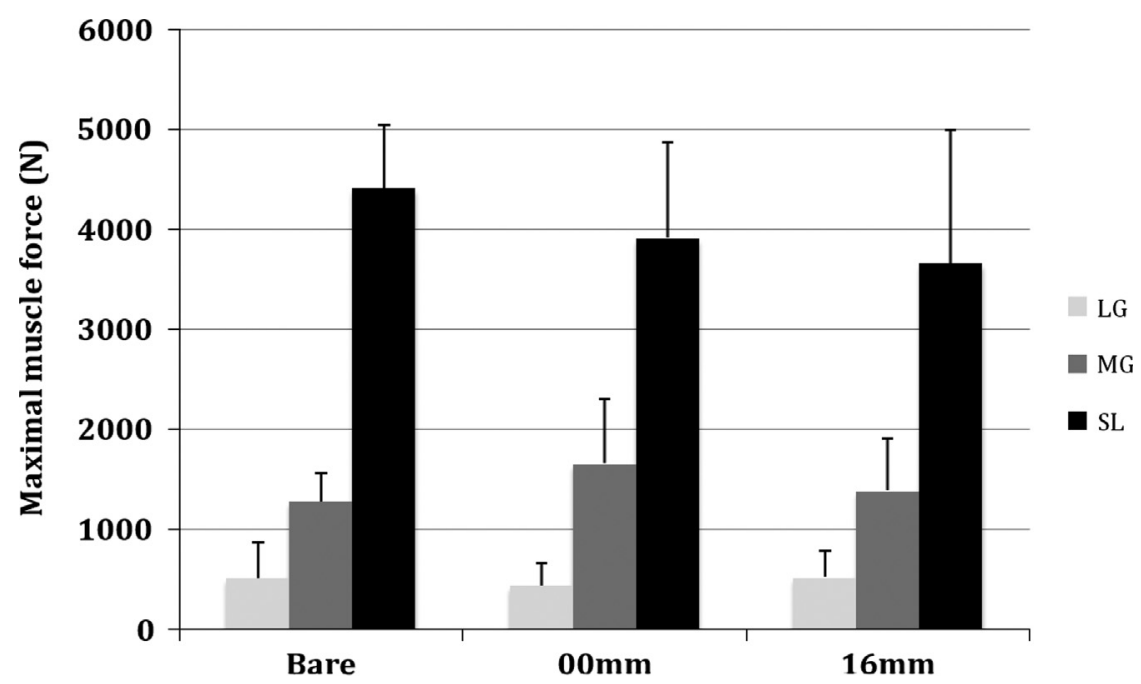

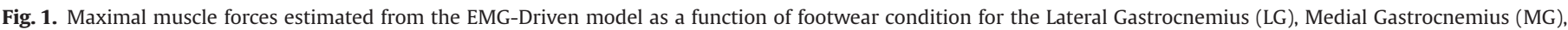
and Soleus (SL) muscles. 


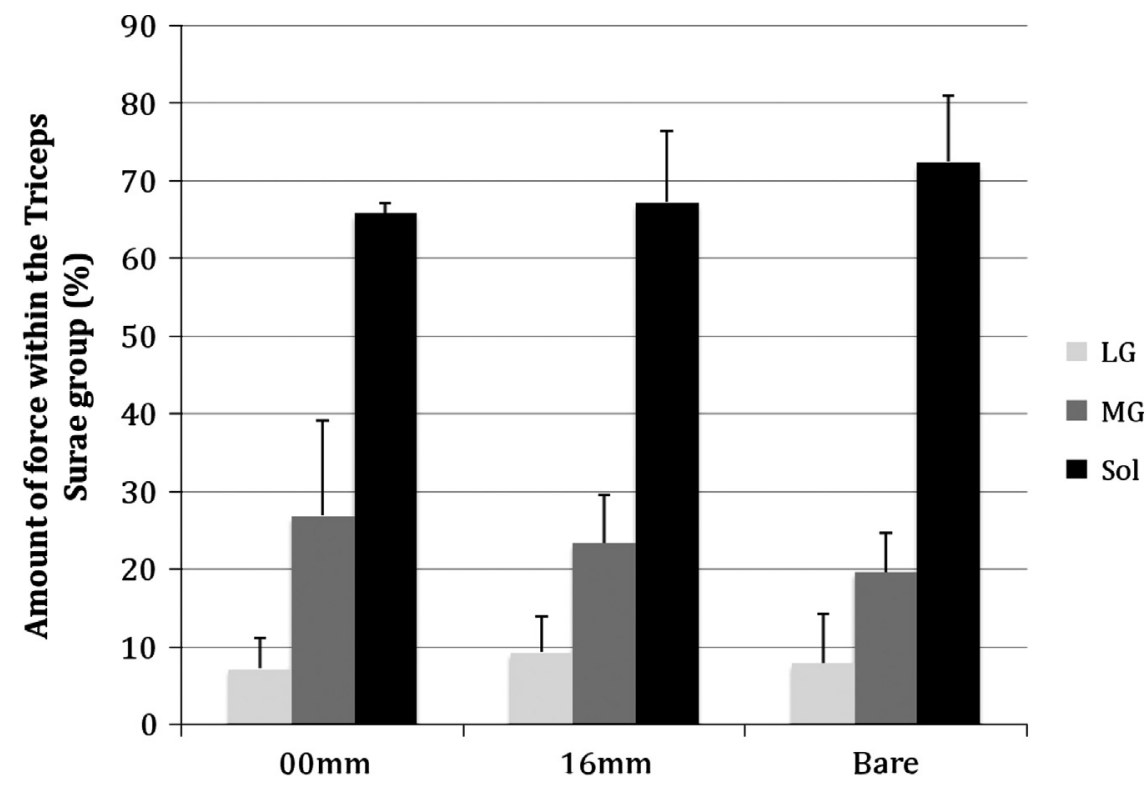

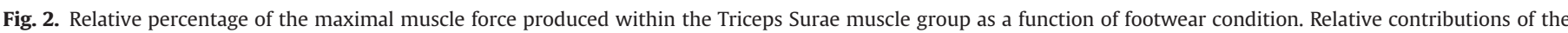
Lateral Gastrocnemius (LG), Medial Gastrocnemius (MG), and Soleus (SL) muscles did not differ through shoe conditions.

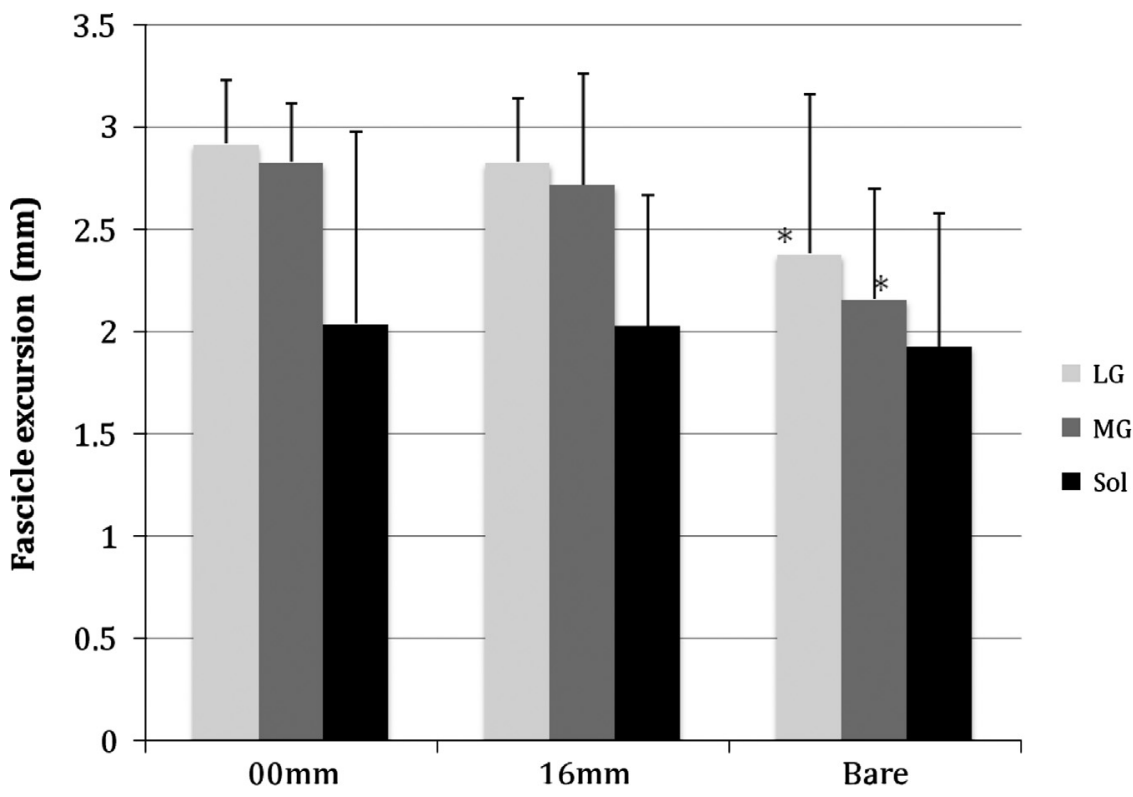

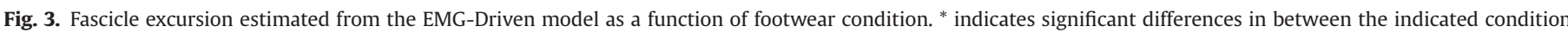
and the other ones. Please note the significantly lower excursion for the bi-articular MG and LG muscles when running barefoot.

Opposite to this result, Perl et al. (2012) showed that habitually barefoot runners have higher Achilles tendon forces when running in barefoot than in shod condition. These highest forces could arise from running patterns of habitually barefoot runners (as in Perl's study) resulting in runners fully adapted to the absence of footwear. Indeed, and although nonsignificant, there was a trend in our study for the Triceps Surae muscle group to increase its maximal force from the $16 \mathrm{~mm}$ to the barefoot condition with the $00 \mathrm{~mm}$ being in between (from $5411.48 \mathrm{~N}, 5884.11 \mathrm{~N}$, and $6046.00 \mathrm{~N}$ respectively for $16 \mathrm{~mm}$, $00 \mathrm{~mm}$, and Bare). Longer habituation durations (i.e., months) could be needed to durably change the running pattern resulting in highest muscle forces in the Triceps Surae muscle group.

Besides the ankle joint kinematics, the only variable that showed a significant influence of the footwear factor was the amplitude of fiber length (i.e., fascicle excursion) for the bi-articular LG and MG muscles. The fascicle excursion represents the amount of stretching and shortening the muscle fiber undergoes during the stance phase. In the present study, the amplitudes of LG and MG fiber lengths were lower in barefoot than in shod conditions. This result is not in line with a recent study (Cronin and Finni, 2013) that showed no difference between barefoot and shod running on MG and Soleus fiber behaviors. However, few subjects of Cronin's study presented a mid- or fore-foot striking pattern while running barefoot (4 out of 10) whereas 7 out of 8 subjects of the present study impacted with the fore- or the midfoot section in the barefoot condition (mean foot/ground angle of 2.06: Altman and Davis, 2012). Foot positioning at touchdown may thus modify fascicle excursion during the stance phase.

The result concerning fascicle excursion is of high interest given that the mean values of the normalized fiber lengths were similar and close to the optimal fiber length (the length where the maximal isometric force can be produced) across the different footwear conditions for all the muscles. A lower fascicle excursion 
together with an averaged fiber length trajectory closer to the optimal fiber length will foster the use of the muscle-tendon structure. Hence, when running barefoot, the bi-articular muscles are operating more isometrically than during shod running, thus enhancing their force output capacities (Biewener and Daley, 2007). Moreover, due to the closeness of the optimal fiber length, these muscles will be operating on a portion of the force-length relationship that is prone to the highest efficiency of the muscle.

It is important to note that the higher range of motion for the ankle joint in barefoot condition is associated with a lower fascicle excursion and a more "biomechanically efficient" contraction of the bi-articular LG and MG muscles. These results reveal a more efficient use of the muscle-tendon structures in barefoot running (Biewener and Daley, 2007; Roberts and Konow, 2013). Indeed, the tendon is known for being able to store and release elastic energy during locomotion, with this storage and release of the energy done with no use of metabolic energy (Roberts and Azizi, 2011; Roberts et al., 1998a, 1998b). Taken together, our results showed that barefoot running could result in a more efficient use of the bi-articular muscle tendon structures by minimizing the work done by the muscle fiber and maximizing the work done by the-energetically economical-tendinous structure. These results are partly confirmed, as Perl et al. (2012) showed that barefoot running is more economical than shod running even when compensating for the shoe mass effect. These authors supposed that energy storage in the longitudinal foot arch may explain this lowest cost. Here we proposed that a more "biomechanically efficient" use of the bi-articular LG and MG muscles-tendon structures could also contribute to this economy in barefoot running.

Previous studies using musculoskeletal simulations have shown during walking that the bi-articular muscles are most effective in favoring the forward progression of the center of mass than the mono-articular muscles (Zajac et al., 2003). Hence changing for a minimalist running shoe could modify the role each muscle has in controlling the motion with a trend to higher muscle forces in the Triceps Surae muscle group and higher energy transfers due to a more efficient use of the bi-articular gastrocnemii muscle-tendon structures (Biewener and Daley, 2007). Future works involving long term adaptation to barefoot running are needed to confirm this hypothesis, similarly deeper investigations of the influence of the ground contact model over the muscle forces are needed.

\section{Conflict of interest}

All authors disclose that there was no conflict of interest regarding this study.

\section{References}

Altman, A.R., Davis, I.S., 2012. A kinematic method for footstrike pattern detection in barefoot and shod runners. Gait Posture 35 (2), 298-300.

Arnold, E.M., Ward, S.R., Lieber, R.L., Delp, S.L., 2010. A model of the lower limb for analysis of human movement. Ann. Biomed. Eng. 38 (2), 269-279.
Barnes, A., Wheat, J., Milner, C.E., 2010. Use of gait sandals for measuring rearfoot and shank motion during running. Gait Posture 32, 133-135.

Biewener, A.A., Daley, M.A., 2007. Unsteady locomotion: integrating muscle function with whole body dynamics and neuromuscular control. J. Exp. Biol. 210 (Pt 17), 2949-2960.

Buchanan, T.S., Lloyd, D.G., Manal, K.T., Besier, T.F., 2004. Neuromusculoskeletal modeling: estimation of muscle forces and joint moments and movements from measurements of neural command. J. Appl. Biomech. 20 (4), 367-395.

Chambon, N., Delattre, N., Guéguen, N., Berton, E., Rao, G., 2014. Is midsole thickness a key parameter for the running pattern? Gait Posture 40 (1), 58-63.

Cronin, N.J., Finni, T., 2013. Treadmill versus overground and barefoot versus shod comparisons of triceps surae fascicle behaviour in human walking and running. Gait Posture 38 (3), 528-533.

De Wit, B., De Clercq, D., Aerts, P., 2000. Biomechanical analysis of the stance phase during barefoot and shod running. J. Biomech. 33, 269-278.

Delp, S.L., Anderson, F.C., Arnold, A.S., Loan, P., Habib, A., Guendelman, E., Thelen, D.G., 2007. OpenSim: open-source software to create and analyze dynamic simulations of movement. IEEE Trans. Biomed. Eng. 54 (11), 1940-1950.

Divert, C., Baur, H., Mornieux, G., Mayer, F., Belli, A., 2005a. Stiffness adaptations in shod running. J. Appl. Biomech. 21, 311-321.

Divert, C., Mornieux, G., Baur, F., Mayer, F., Belli, A., 2005b. Mechanical comparison of barefoot and shod running. Int. J. Sports Med. 26 (7), 593-598.

Fukano, M., Nagano, Y., Ida, H., Fukubayashi, T., 2009. Change in tibial rotation of barefoot versus shod running. Footwear Sci. 1 (1), 19-23.

Gerus, P., Rao, G., Berton, E., 2012. Subject-specific tendon-aponeurosis definition in hill-type model predicts higher muscle forces in dynamic tasks. PloS One 7 (8), e44406.

Hatala, K.G., Dingwall, H.L., Wunderlich, R.E., Richmond, B.G., 2013. Variations in foot strike patterns during running among habitually barefoot populations. PloS One 8 (1), e52548.

Hamill, J., Russel, E.M., Gruber, A.H., Miller, R., 2011. Impact characteristics in shod and barefoot running. Footwear Sci. 3 (1), 33-40.

Hug, F., Turpin, N.A., Guével, A., Dorel, S., 2010. Is interindividual variability of EMG patterns in trained cyclists related to different muscle synergies? J. Appl. Physiol. 108 (6), 1727-1736.

Kerrigan, D.C., Franz, J.R., Keenan, M.D., Dicharry, J., Della Croce, U., Wilder, R.P., 2009. The effect of running shoes on lower extremity joint torques. PM\&R 1, 1058-1063.

Lieberman, D.E., Venkadesan, M., Werbel, W.A., Daoud, A.I., D’Andrea, S., Davis, I.S., Ojiambo Mang'Eni, R., Pitsiladis, Y., 2010. Foot strike patterns and collision forces in habitually barefoot versus shod runners. Nature 463 (7280), 531-535.

Lloyd, D.G., Besier, T.F., 2003. An EMG-driven musculoskeletal model to estimate muscle forces and knee joint moments in vivo. J. Biomech. 36 (6), 765-776.

Morio, C., Lake, M.J., Gueguen, N., Rao, G., Baly, L., 2009. The influence of footwear on foot motion during walking and running. J. Biomech. 42, 2081-2088.

Paquette, M.R., Zhang, S., Baumgartner, D.L., 2013. Acute effects of barefoot, minimal shoes and running shoes on lower limb mechanics in rear and forefoot strike runners. Footwear Sci. 5 (1), 9-18.

Perl, D.P., Daoud, A.I., Lieberman, D.E., 2012. Effects of footwear and strike type on running economy. Med. Sci. Sports Exerc. 44 (7), 1335-1343.

Roberts, T.J., Azizi, E., 2011. Flexible mechanisms: the diverse roles of biological springs in vertebrate movement. J. Exp. Biol. 214 (Pt 3), 353-361.

Roberts, T.J., Chen, M.S., Taylor, C.R., 1998a. Energetics of bipedal running. II. Limb design and running mechanics. J. Exp. Biol. 201 (Pt 19), 2753-2762.

Roberts, T.J., Konow, N., 2013. How tendons buffer energy dissipation by muscle. Exerc. Sport Sci. Rev. 41 (4), 186-193.

Roberts, T.J., Kram, R., Weyand, P.G., Taylor, C.R., 1998b. Energetics of bipedal running. I. Metabolic cost of generationg force. J. Exp. Biol. 201 (Pt 19), $2745-2751$.

von Tscharner, V., Goepfert, B., Nigg, B.M., 2003. Changes in EMG signals for the muscle tibialis anterior while running barefoot or with shoes resolved by nonlinearly scaled wavelets. J. Biomech. 36, 1169-1176.

Williams, D.S., McClay, I.S., Manal, K.T., 2000. Lower extremity mechanics in runners with a converted forefoot strike pattern. J. Appl. Biomech. 16, 210-218.

Zajac, F.E., Neptune, R.R., Kautz, S.A., 2003. Biomechanics and muscle coordination of human walking: Part II: lessons from dynamical simulations and clinical implications. Gait Posture 17 (1), 1-17. 